исследования; не испытывали трудностей при разрешении конфликтов 17 человек на контрольном этапе, по сравнению с один человеком на констатирующем этапе исследования.

Таким образом, результаты диагностики показали, что разработанная нами программа повышения квалификации по управлению межличностными конфликтами в образовательной организации эффективна, о чем свидетельствует положительная динамика у педагогов при управлении межличностными конфликтами. Данная программа рекомендована педагогическим советом для обучения педагогических работников образовательных организаций.

\title{
Лuтература:
}

1. Базелюк В.В. Разрешение педагогических конфликтов. Челябинск: ЧГПУ, 2005. $169 \mathrm{c.}$

2. Темина С.Ю. Конфликты школы и «школа конфликтов» // Введение в конфликтологию образования. М.: Моск. психол.-соц. ин-т; Воронеж: НПО МОДЭК, 2011. 144 с.

3. Шадриков В.Д. Новая модель специалиста: инновационная подготовка и компетентностный подход // Высшее образование сегодня. 2015. № 9. C. 17-22.

$$
* * *
$$

\section{Щеткина М.А.,} аспирант, ассистент преподавателя, Институт иностранных языков, Московский городской педагогический университет; г. Москва, Россия, veolet7@mail.ru

\section{Имидж руководителя как часть организационной культуры образовательной организации}

Аннотация: в статье рассмотрена проблема формирования имиджа руководителя в рамках образовательной организации и влияние имиджа руководителя 
на ее организационную культуру. Обозначена взаимосвязь между управленческой деятельностью руководителя и качеством работы элементов организационной культуры, определены аспекты имиджа руководителя, которые влияют на формирование организационной культуры. Описаны особенности управленческой деятельности руководителя в образовательной организации и характер формирования имиджа в организациях данного типа. Раскрыта проблема влияния имиджа руководителя на имидж образовательной организации. Определены составляющие имиджа руководителя образовательной организации.

Ключевые слова: имидж руководителя; имидж организации; организационная культура; образовательная организация; управленческая культура руководителя; самопрезентация; коммуникация; стиль руководства; элементы имиджа.

Maria Schetkina,

Ph.D. Student, Teaching Assistant, Institute of Foreign Languages,

Moscow City University; Moscow, Russia, veolet7@mail.ru

\title{
Image of the leader as a part of the organizational culture of the educational organization
}

\begin{abstract}
: the article discusses the problem of forming the image of a leader within an educational institution and the influence of the image of a leader on the organizational culture of an educational institution. The relationship between the manager's managerial activity and the quality of work of the elements of the organizational culture is indicated, aspects of the manager's image that affect the formation of the organizational culture are determined. The features of the managerial activity of the head in an educational institution and the nature of the formation of the image in institutions of this type are described. The problem of the influence of the image of the head of an educational institution on the image of an organization is revealed. The components of the image of the head of an educational institution have been determined.
\end{abstract}

Keywords: image of a leader; image of an organization; organizational culture; educational institution; managerial culture of a leader; self-presentation; communication; leadership style; elements of image.

Одна из задач организационной культуры - обеспечение внутреннего единства и интеграции сотрудников. Качественное решение данной задачи играет важную роль при регулировании внутриорганизационных 
процессов и отношений между членами рабочего коллектива. Обмен информацией и профессиональное взаимодействие должны осуществляться в пределах установленных границ открытости и в соответствии с едиными образцами желательного и нежелательного поведения внутри организации. Принятие и соблюдение соглашений в рабочем коллективе по вышеприведенным вопросам в процессе формирует присущую данной организации культуру.

Организационная культура - это система общих ценностей, правил и норм поведения, принимаемых членами организации [1, с. 68]. Согласно принципам организационной культуры, в образовательной организации формируются внутренние и внешние отношения, закладывается философия организации, устанавливается корпоративная этика и определяются критерии принятия управленческих решений. Качество работы вышеперечисленных элементов организационной культуры напрямую зависит от деятельности руководителя, от уровня его управленческой культуры и в конечном счете влияет на приобретение неповторимого имиджа образовательной организации. При этом значительное влияние на успешность работы образовательной организации оказывает личность руководителя, сформированный им имидж, который состоит из следующих элементов: манера поведения, ораторские навыки, способность внушать доверие, внешний облик, грамотность и эрудированность и ценностно-стратегические ориентиры. Проблема формирования имиджа руководителя, который отвечает ценностным установкам образовательной организации и одобряется общественностью, весьма актуальна и своевременна. В докладе мы представим имидж руководителя как важный структурный компонент организационной культуры, рассмотрим качество формирования элементов имиджа руководителя как инструмент управления образовательной организацией и определим составляющие имиджа руководителя образовательной организации.

Современные исследователи в области социологии управления изучают различные аспекты взаимосвязи имиджа с организационной культурой. К.А. Мызрова и К.А. Козлова анализируют понятия «имидж руководителя» и «имидж организации» [2]. К.А. Яковлева проводит параллель между организаций работы руководителя и эффективностью работы всей организации [7]. Л.А. Церникель в своей статье о культуре профессионального развития выделяет имидж руководителя как одну из главных составляющих успешной деятельности организации [6]. Именно имидж руководителя (профессионализм, интеллектуально-личностные качества, 
социально групповые качества, эмоционально-волевые свойства и т. д.), по мнению вышеперечисленных авторов, задает культурный вектор развития всей организации.

В литературе имеется множество различных определений понятия имидж. Наиболее распространены следующие определения. Имидж - это сложившийся в массовом сознании и имеющий характер стереотипа, эмоционально окрашенный образ чего-либо или кого-либо [1, с. 68]. Имидж (от англ. image - образ) - целеустремленно формируемый образ какогонибудь лица, предмета, явления, призванный произвести на кого-нибудь эмоциональное и психологическое воздействие с целью его рекламы, популяризации. Применительно к руководителю это оценка его моральноличностных, интеллектуальных, профессиональных и этических качеств окружающими людьми. При изучении трудов вышеперечисленных и других исследователей становится очевидной взаимозависимость между имиджем руководителя и качеством организационной культуры. Имидж, как один из элементов управленческой культуры руководителя, влияет на его решения при формировании организационной культуры, от качества которой в свою очередь зависит имидж организации в целом и руководителя в частности. Успешный имидж организации будет некоторое время положительно работать на нового руководителя с еще формирующимся имиджем. В то же время сильный руководитель с положительным имиджем способен за несколько лет поднять имидж организации со слабым спросом. Руководитель оказывает влияние на следующие структурные элементы организационной культуры: корпоративный язык; границы группы и критерии ее членства; власть и социально-должностной статус; поощрения и штрафы; внутрикорпоративные отношения; и идеологию организации. В рамках системного подхода имидж руководителя можно рассматривать как важный формирующий структурный компонент организационной культуры, который оказывает влияние на все ее элементы.

Говоря об имидже руководителя образовательной организации, необходимо рассмотреть специфику работы данной структуры, ее цели и задачи. Согласно действующему Федеральном закону «Об образовании в Российской Федерации», образовательная организация - это некоммерческая организация, осуществляющая на основании лицензии образовательную деятельность в качестве основного вида деятельности в соответствии с целями, ради достижения которых такая организация создана [5, ст. 2]. На руководителей образовательных организаций возложена весьма деликатная функция: практически согласовать, увязать в единое 
целое реальные противоречивые формы проявления интересов государства, педагогического коллектива, отдельных сотрудников, в том числе и свои личные, а также уметь реализовать в учебно-воспитательной деятельности идеи и находки творчески работающих преподавателей, педагогов-новаторов и ученых.

В основе деятельности руководителя образовательной организации лежит ряд управленческих и образовательных целей и принципов.

Среди управленческих принципов выделяют следующие: не ограничивать, а направлять, не запрещать, а помогать, не командовать, а руководить. При этом управление будет эффективно только при применении современных образовательных технологий, инновационных методов обучения и развитии новых организационных форм.

Среди образовательных изелей выделяют развитие общей культуры, морально-правовых устоев членов общества, развитие личностного потенциала и овладение прочными знаниями, умениями и навыками с возможностью их применения на практике.

Существуют два пути построения имиджа: это имидж на основе самораскрытия собственной личности, доверия к окружающим и имиджманипуляция, основанный на сокрытии своих истинных целей, мотивов и демонстрации тех качеств, которыми человек на самом деле не обладает $[6$, c. 150]. Безусловно, в образовательной организации, где важную роль играет неуклонное следование ценностным ориентирам в вопросах воспитания собственным примером, естественным и единственно возможным вариантом для формирования внутри коллективных отношений будет имидж, построенный на самораскрытии своей личности. Ведь в процессе длительного контакта с педагогическим коллективом, сотрудники выявляют корысть с помощью невербальных сигналов (жестов, мимики, поз), а также по средствам оценивания мотивов и поступков руководителя. Как следствие, имидж-манипуляция теряет свою силу, а руководителя, выбравшего данный путь построения имиджа, неминуемо ожидает частая смена рабочих мест.

При этом для успешной самопрезентации руководителя в средствах массмедиа и внешних контактах с представителями других организаций, важно выработать свой неповторимый стиль, в котором сочетаются актуальный внешний образ и отлаженная деловая коммуникация. В формировании убедительного, актуального внешнего образа, разумным будет со стороны руководителя заручиться поддержкой специалистов в вопросах стиля. Немаловажную роль в современном технологично развитом 
мире, будет и формирование имиджа в информационных платформах, социальных сетях и умение презентовать себя с помощью видеотрансляции. Информацию, которая размещается на странице руководителя в социальной сети, следует тщательно фильтровать, согласно целям своего имиджа. От успешности внешней самопрезентации руководителя во много зависит рейтинг и в том числе привлечение спонсоров и союзников в работу организации. Такие элементы имиджа руководителя, как внешность, психотип, тембр речи, статус, личная миссия и т. д., являются управленческими инструментами в руководстве образовательной организацией.

Говоря об элементах, формирующих имидж, необходимо выделить стиль руководства. Он определяет всю систему формальных и неформальных отношений людей в организации. Адекватный стиль управления, выбранный с учетом сложившейся управленческой ситуации и уровня развития коллектива, повышает привлекательность имиджа руководителя. Это повышает его профессиональный и личный авторитет в системе производственных и межличностных отношений, что существенно влияет на эффективность управления и карьерные перспективы такого руководителя. Человек и его имидж должны быть целостными, взаимодополняющими друг друга. В противном случае, рано или поздно у персонала организации возникают обоснованные подозрения в неискренности руководителя, ощущение, что он манипулирует своими сотрудниками. Последовательность и предсказуемость поведения руководителя тоже безусловно важны в формировании положительного, доверительного имиджа. В своей работе Н.В. Техтелева приводит следующие технологические этапы формирования имиджа: прорисовка публичной идентичности; инвентаризация; коррекция личной идентичности; выбор средств для построения желаемого образа; вхождение в образ [4, с. 79].

Еще один важный элемент это - система коммуникаций. Коммуникация раскрывает уровень интеллектуально-личностного и профессионального развития человека и его эмоциональной вовлеченности в дело, которым он занимается. Все это формирует аттракцию (притяжение, привлекательность). Грамотная и культурная речь станет хорошим инструментом для успешных коммуникаций. Иногда, используя этот инструмент, внешне малопривлекательный человек вызывает симпатию и даже может привлечь на свою сторону людей, что поможет решить множество производственных проблем. Поэтому успешное коммуникация и правильно подобранный стиль руководства повышают привлекатель- 
ность имиджа. Именно руководитель организует работу по сбору управленческой информации. Как указывает Э.Н. Рычихина, качество информационного обеспечения во многом определяется общей подготовкой руководителя и сложившейся практикой организации [3, с. 26].

Имидж руководителя образовательной организации - это многоаспектное понятие, включающее гармонично соответствующие друг другу внешний облик и набор профессиональных качеств, требующих постоянного развития и совершенствования, которые формируют единый образ, основанный на морально-нравственных ценностях и самораскрытии личности, выражающийся в установлении доверительных отношений с педагогическим составом, в высоком уровне межведомственных коммуникаций, либеральном стиле руководства и успешном применении в управлении образовательной организацией современных технологий.

\section{Лuтература:}

1. Козлова Н.П. Формирование положительного имиджа и деловой репутации компании // Вестник АГТУ. Сер. Экономика. 2011. № 1. C. 67-71.

2. Мызрова K.A., Козлова К.A. Имидж руководителя как важный элемент организационной культуры организации // Научный диалог: Экономика и менеджмент. Сб. науч. тр. по материалам XIII международной научно-практ. конф. 8 марта 2018 г. СПб.: ЦНК МОАН, 2018. С. 30-34.

3. Рычихина Э.Н. Мониторинг в системе социального управления муниципальным образованием. Автореф. дис. ... д-ра социол. наук. M., 2010. 47 c.

4. Техелева Н.В. Технологии формирования имиджа руководителя // Известия академии управления: теория, стратегии, инновации. 2011. № 1. С. 77-81.

5. Федеральный закон от 29.12.2012 № 273-Ф3 (ред. от 24.03.2021) «Об образовании в Российской Федерации» // КонсультантПлюс. URL: http://www.consultant.ru/document/cons_doc_LAW_ 140174/ (дата обращения: 06.06.2021).

6. Церникель Л.А. Культура профессионального развития и роста руководителя образовательного учреждения в логике мотивационного программно-целевого управления // Модернизация профессионально-педагогического образования: тенденции, стратегия, зарубежный 
опыт. Барнаул, 13-15 октября 2014 г. Барнаул: Алтайская гос. пед. академия, 2014. С. 149-150.

7. Яковлева К.А. Личность руководителя как приоритетный фактор формирования и развития позитивного имиджа организации // Научные записки Орловского гос. ун-та экономики и торговли. 2014. № 1 (9). C. 262-266.

$$
* * *
$$

Яковлева А.В., заместитель декана факультета теологии, Московский исламский институт; г. Москва, Россия, ami27.86.27@gmail.com

\title{
Информационно-образовательные технологии как ресурс развития исламской образовательной организации
}

Аннотация: статья посвящена проблеме использования современных информационно-образовательных технологий в исламской образовательной организации. В условиях конфессионально обусловленной учебно-воспитательной среды цифровизация образовательного пространства вызывает ряд вопросов и опасений, касающихся сохранения качества образовательных результатов. Рассмотрены теоретические основы внедрения информационных технологий в процесс обучения и практика их применения в исламском институте.

Ключевые слова: информационные технологии; дистанционное обучение; исламская образовательная организация; цифровизация; высшее образование.

\author{
Albina Yakovleva, \\ Deputy Dean of the Faculty of Theology, \\ Moscow Islamic Institute; \\ Moscow, Russia, \\ ami27.86.27@gmail.com
}

\section{Information and educational technologies as a resource for the development of an Islamic educational organization}

\begin{abstract}
: the article is devoted to the problem of using modern information and educational technologies in an Islamic educational organization. In the context of a confessionally conditioned educational environment, the digitalization of the educational
\end{abstract}

